\title{
Опыт применения отсроченных кишечных анастомозов при перитоните
}

\author{
V. V. BOYKO, YU. V. IVANOVA, E. V. MUSHENKO, S. A. SAVVI, A. N. HAMIDOV, A. N. KUDREVYCH \\ SI "Institute of General and Urgent Surgery of AMS of Ukraine", Kharkiv
}

\section{THE EXPERIENCE APPLICATION OF DELAYED BOWEL ANASTOMOSIS AT PERITONITIS}

\begin{abstract}
В статье представлен опыт лечения больных, нуждающихся в резекции участков кишечной трубки в условиях перитонита. Была показана необходимость формирования разгрузочных стом при формировании первичного межкишечного анастомоза. При высоком риске несостоятельности кишечных швов обоснована тактика формирования отсроченных кишечных анастомозов по разработанной методике. Применение предложенного подхода позволило снизить количество послеоперационных осложнений и летальность.

The experience of treatment of patients that are needed the bowel resection at peritonitis is presented in the article. It was shown the necessity of dumping stomas if the primary bowel anastomosis is planned to perform. The developed tactics of delayed bowel anastomosis must be used if the high risk of anastomosis' incompetence exists. Using of such an approach leads to decreasing of postoperative morbidity and mortality.
\end{abstract}

Хирургическое лечение перитонита до настоящего времени остается одной из центральных проблем экстренной хирургии. Если по устранению первопричины перитонита разработаны самые разные методики, то проблема предупреждения связанных с этим осложнений продолжает дискутироваться в специальной литературе $[1,2]$. Многолетний опыт убеждает, что формирование кишечных анастомозов и наложение швов в условиях воспаленной брюшины и ишемии сопровождаются угрозой возникновения их несостоятельности, это тяжелое осложнение в 30-40\% случаев ведет к развитию послеоперационного перитонита, а в 40 $60 \%$ случаев является причиной летального исхода [3-5].

С целью улучшения результатов лечения больных, которым в условиях перитонита необходимо выполнение резекций участков кишечной трубки, в клинике института разработан новый хирургический подход, который с успехом применяется с 2008 года.

При высокой резекции тонкой кишки выполняем двухствольную тонкокишечную стому с межкишечным соустьем между приводящей и отводящей петлями, которое может быть выведено забрюшинно, фиксировано на уровне передней брюшной стенки, либо оставлено в брюшной полости при условии декомпрессии интубационным зондом (рис. 1), либо выполняем формирование У-образной стомы (рис. 2).

Показания к указанным типам оперативных вмешательств существенно ограничены, однако они все же могут иметь место, особенно в случаях, когда нужно обеспечить кишечный пассаж уже в раннем послеоперационном периоде (“высокие резекции" тонкой кишки).

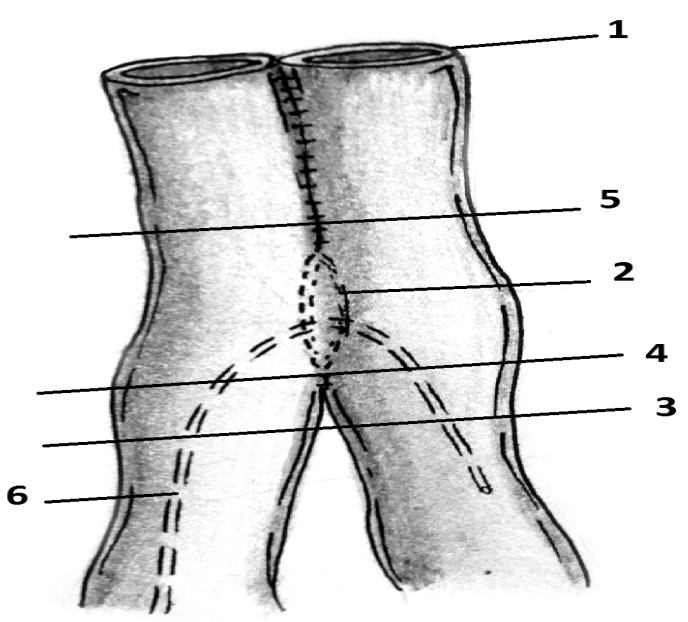

Рис. 1. Двухствольная тонкокишечная стома (1) с межкишечным соустьем (2), выведенным забрюшинно (3), фиксированным на уровне брюшной стенки (4) или в брюшной полости (5) при условии декомпрессии анастомотической камеры интубационным зондом. 


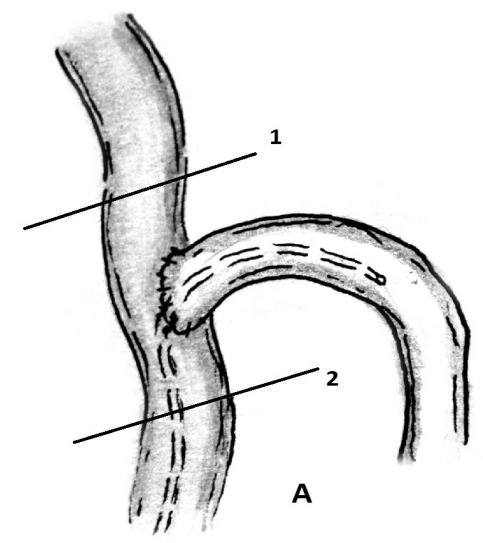

Рис. 2. У-образная тонкокишечная стома с межкишечным соустьем “конец в бок” при условии интубации кишечника.

При высоком риске несостоятельности швов кишечника мы полностью отказались от наложения первичных анастомозов. Это стало тем более обосновано, когда в клинике была разработана методика формирования отсроченных межкишечных соустий через двухствольную стому. Данная технология, по нашему мнению, может быть удачной альтернативой концевым стомам. Суть разработанной технологии состоит в следующем. После выполне- ния резекции кишки проксимальный и дистальный участки ее сшивают между собой двумя рядами швов с расстоянием между ними не менее 1,5 cм по противобрыжеечным краям. На передней брюшной стенке формируют двухствольную кишечную стому (тонкотонкокишечную, тонкотолстокишечную или толстотолстокишечную в зависимости от уровня резекции кишки) таким образом, чтобы часть сшитой кишки находилась в брюшной полости. Через приводящую и отводящую петли при помощи зажима вводят компрессионное устройство диаметром 1,5-2,5 см на удерживающих нитях с фиксацией его изнутри в изолированной серозно-мышечными швами зоне. В результате компрессии кишечная стенка некротизируется по линии сдавления, образуется межкишечное соустье, компрессионное устройство при помощи удерживающих нитей выводится через стому наружу и удаляется на 5-8-е сутки после операции.

После восстановления кишечного пассажа по сформированному таким образом межкишечному соустью стома ликвидируется внебрюшинно (рис. 3,4 ).

Разработанная хирургическая тактика применена у 54 пациентов с перитонитом, а также умеренным и высоким риском развития несостоятельности анастомозов. Осложненное течение после-

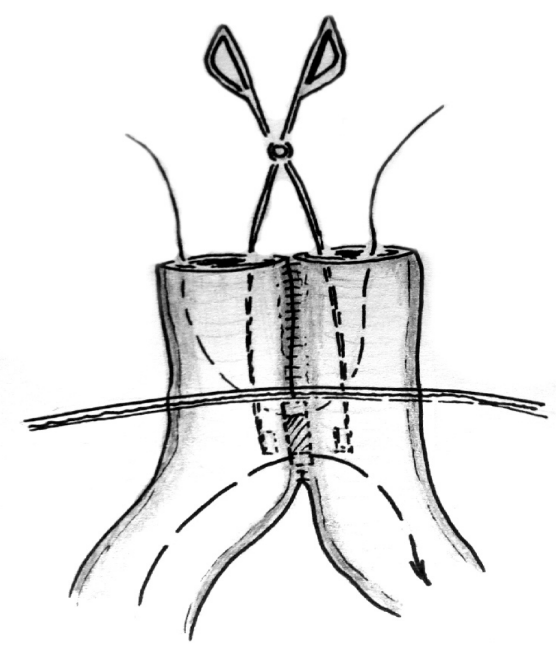

Рис. 3. Формирование отсроченных межкишечных анастомозов.
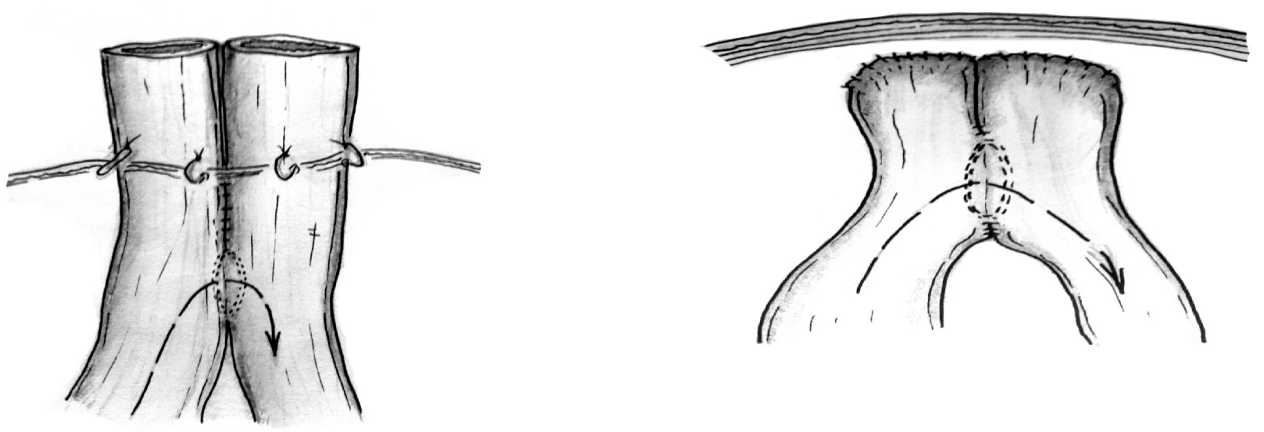

Рис. 4. Варианты расположения межкишечных анастомозов. 
операционного периода отмечено у 13 \% больных, среди них частичная несостоятельность анастомоза отмечена в $1,9 \%$, перфорации острых язв - в $1,9 \%$ случаев, динамическая кишечная непроходимость - в 3,8 \% (устранена с помощью консервативных мероприятий), в 3,7 \% случав течение послеоперационного периода осложнилось развитием нагноения ран. Релапаротомия потребовалась в 3,8 \% наблюдений. Умерли 2 (3,8 \%) больных, в одном случае причиной смерти была острая ле-

\section{СПИСОК ЛИТЕРАТУРЫ}

1. Программированные релапаротомии при перитоните / Г. Р. Аскерханов, А. Г. Гусейнов, У. З. Загиров [и др.] // Хирургия. -2000 . - № 8. - С. 20-23.

2. Абдоминальный сепсис: современный взгляд на нестареющую проблему / Б. Р. Гельфанд, С. З. Бурневич, П. В. Подачин [и др.] // Вестник интенсивной терапии. - 1998. - № 1. - С. 12-16.

3. Гельфанд Е. Б. Абдоминальный сепсис: интегральная оценка тяжести состояния больных и полиорганной дисфункции / гочно-сердечная недостаточность и в одном тромбоэмболия легочной артерии. Всем выжившим больным в разные сроки выполнено внебрюшинное закрытие свищей.

Bыводы. Формирование отсроченных кишечных анастомозов показано в ургентной хирургии при умеренном и высоком риске несостоятельности кишечных швов и способствует уменьшению частоты послеоперационных осложнений и снижению уровня летальности.

Е. Б. Гельфанд, В. А. Гологорский, Б. Р. Гельфанд // Анестезиология и реаниматология. - 2000. - № 3. - С. 29-33.

4. Гнойный перитонит. Патофизиология и лечение / [А. Я. Цыганенко, В. В. Бойко, И. А. Криворучко и др.]. - Х. : Контраст, 2002. $-280 \mathrm{c}$.

5. Кузин М. И. Лечение перитонита с полиорганной недостаточностью / М. И. Кузин, С. А. Дадвани, М. И. Сорокина // Хирургия. - 1994. - № 5. - С. 8-13. 